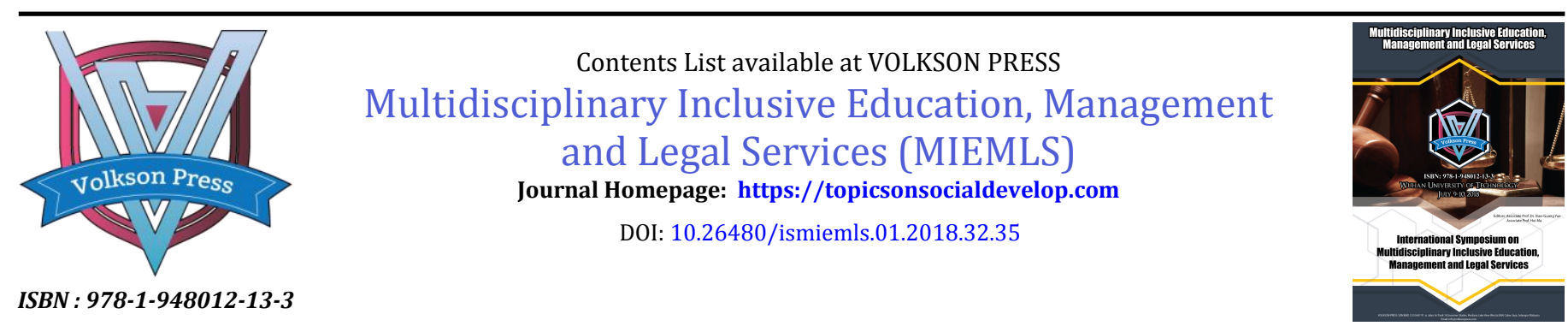

\title{
COMPREHENSIVE VIEW ON THE EFFECT OF ARTIFICIAL INTELLIGENCE ON EMPLOYMENT
}

\author{
He Ping, Gao Yao ying \\ School of Arts and Law, Whut, Wuhan, China \\ *Corresponding Author Email: 1321683598@qq.com
}

This is an open access article distributed under the Creative Commons Attribution License, which permits unrestricted use, distribution, and reproduction in any medium, provided the original work is properly cited.

\section{ARTICLE DETAILS}

\section{Article History:}

Received 26 June 2018 Accepted 2 July 2018 Available online 1 August 2018

\section{ABSTRACT}

In recent years, with the rapid development of robots, artificial intelligence has gradually replaced a part of jobs and caused the problem of unemployment, which caused the panic of the robot substituting man. In fact, human beings have seen more of the substitution effect brought by artificial intelligence to employment, but neglected its creative effect, although the effect of suppressing substitution effect is not optimistic. Therefore, it is urgent to base on the long-term development and take active measures to alleviate the unemployment caused by artificial intelligence.

\section{KEYWORDS}

Artificial intelligence, Employment, Uemployment, Creative effect, Substitution effect.

\section{INTRODUCTION}

Science and technology is the first productive force, and scientific and technological innovation is the driving force to promote economic growth; Employment is a matter of the people's livelihood, full employment is conducive to social stability. However, there is no natural compatible relationship between them. On the one hand, science and technology innovation is conducive to creating jobs and promoting employment [1]. On the other hand, it will eliminate the jobs that cannot keep up with the new technology, hinder employment, how to maximize strengths and avoid weaknesses is a difficult problem. In recent years, with the victory of Alpha Go over go master Li Shi shi, artificial intelligence once again came into the human field of vision, which also triggered a new thinking: artificial intelligence is convenient to our lives at the same time, will cause large-scale unemployment? First, we analyze the effect of artificial intelligence on employment from the perspective of theory.

\section{THEORETICAL ANALYSIS: THE INFLUENCE OF ARTIFICIAL INTELLIGENCE ON EMPLOYMENT}

Human acceptance of new things varies from person to person, coupled with the double-edged role of artificial intelligence technology to society, people express their own views on it, resulting in a lot of controversy [2]. At present, synthesizing the theoretical analysis of experts and scholars, the influence of artificial intelligence on employment includes destruction mechanism and creation mechanism. The creation mechanism is also the compensation effect. Artificial intelligence can promote economic growth, create new jobs and promote employment. The destruction mechanism is the substitution effect, the new technology replaces the old technology, and the jobs relying on the old technology are replaced accordingly, which will inevitably lead to unemployment [3]. As technology continues to deepen into human life, the problem of unemployment will intensify. At present, more and more people from all aspects of life realize that artificial intelligence is a substitute for employment, which in turn reinforces the panic that "people will be replaced by robots." In order to find the corresponding solution to the problem, we must firstly clarify the influence mechanism of artificial intelligence on employment theoretically.
2.1 The destructive effect of artificial intelligence on employment

The technological revolution is the concentrated manifestation of technological progress to a certain extent. It promotes the development of economy and, as the support of industrial revolution, leads to the transformation of social employment structure. In theory, artificial intelligence, as a new technology, has brought about the increase of labor productivity. When the scale of production is fixed, the demand for labor force will be reduced and the employment post will be reduced by using the method of variable analysis [4]. Furthermore, technological advances will reduce costs, make more efficient use of resources, and increase capital productivity. In this way, the substitution effect of machines will become more and more the trend of the times. For example, the technological innovation and productivity increase proposed by Xiong Bide, which will cause a short-term increase in the demand for major elements used in the production of new products [5]. However, the saving effect of process innovation will lead to a decrease in the demand for labor, which will lead to higher unemployment rate. The damage effect will be analyzed from the change of labor mode, the change of labor market demand and the change of enterprise management.

\subsubsection{Changes in the way of work}

Technological progress will lead to changes in the tools used, just as machinized mass production replaced handicraft labor after the first industrial revolution. With the further application of artificial intelligence technology, automation and intelligent production will be applied to human life on a large scale [6]. The production process based on technology and capital-intensive methods, advanced and practical equipment will increase the productivity of labor, and the utilization of raw materials will also increase. With the continual expansion of production scale, capital will further replace physical labor. As a result, the number of jobs supported by primitive backward labor will continue to decrease, which will have a strong impact on the employment structure as a whole. 


\subsubsection{Changes in labor market demand}

Artificial intelligence technology will not only affect employment through the change of human production mode, but also have a negative impact on labor demand. Because from the current situation in which artificial intelligence has been applied in life, it can be predicted that in the future it will occupy a large number of procedural, low-knowledge areas of work [7]. The "five-second rule" has been put forward by quite a number of scholars in the theoretical circle. It means that artificial intelligence will in the future be able to completely or largely replace the work in which humans are able to make decisions and behaviors through brain thinking in five seconds.

As a result, "blue collars" such as customer service, ordering, cashier and so on have the theoretical possibility of being replaced, even involving some "white collar" jobs. In 2005, for example, bank tellers and so on in the financial industry can be replaced, and the five-second rule coincides with existing theories [8]. That is, technological advances include skill preference and skill degradation. Skill preference refers to the fact that technological progress tends to absorb highly skilled labor force, while skill degradation tends to low skilled labor force. Finally, the demand change of labor market results from the joint action of both. From the experience of several revolutions caused by technological progress in history, technological progress tends to increase the demand for highly skilled labor force, thus reducing the demand for low-skilled labor force, which leads to a wave of unemployment [9].

\subsubsection{Changes in management staffing}

With the wide application of artificial intelligence technology, enterprises not only reduce the demand for labor in the manufacturing layer, but also reform and change the staffing of management [10]. For example, in order to adapt to the change of consumers' homogeneous consumption to individualized consumption, the mode of production has changed from single production to mass production, and after mass production has been converted to lean production, not only ordinary manufacturing workers have lost their jobs. Some jumbled management also need to streamline staff to improve management efficiency.

\subsection{The employment creation effect of artificial intelligence}

The new technology is a double-edged sword, which not only brings adverse effects to employment, but also creates employment opportunities, but it is only often ignored its compensation effect [11]. In theory, the wide application of the new technology itself, the development and maintenance of new jobs and the demand for the corresponding skilled labor force. Secondly, the further application of new technology will form new industries and departments and create new jobs. Third, the use of advanced technology can improve labor productivity, save costs, increase liquidity, thereby expanding the scale of production, stimulating labor demand, and creating employment.

\subsubsection{Increasing income of residents to stimulate demand}

The wide application of new technology can reduce production cost, improve labor productivity and promote economic development and social progress. The increase of residents' income is accompanied by the further improvement of living standard, which stimulates the total social demand, which leads to the expansion of the production scale of a large number of enterprises, thus increasing the demand for labor force.

\subsubsection{New technologies themselves create jobs}

At the beginning of new technology application, it is a new thing for human beings, and its application and mastery require human beings to re-learn and adapt slowly. Artificial intelligence technology is especially true for human society, it is to turn human intelligence material into artificial intelligence, need to train a large number of professionals, master this new technology [12]. At the same time, artificial intelligence will produce many problems in the process of application, which need to be solved in the first place, which involves maintenance and development, such as the maintenance of robots. All these provide favorable conditions for job creation.

\subsubsection{Expanding the scope of the economy to create jobs}

When the new technology is applied to the human society to a certain scale and degree, the old sectors and industries will gradually be replaced by the new industries and departments, putting forward new requirements to people, and the economic scope will be further expanded, and the industry develops in a broader and deeper direction. New products, new sectors springing up, will also stimulate new social demand, and eventually new jobs and opportunities will follow. Moreover, the creative effect of artificial intelligence is reflected in reducing labor intensity, improving labor environment, enhancing workers' comfort and satisfaction, and improving the quality of employment.

\subsection{The overall analysis of the impact of artificial intelligence on employment}

From the above theoretical analysis, we can see that artificial intelligence technology not only has a destructive effect on employment, but also has a certain creative effect on employment. Moreover, its influence on employment also has the characteristics of general expansion, time difference and labor group bias. But what people see more is its destructive effect, because it can form in the short term and have influence in real life. With the further application of artificial intelligence technology, its substitution effect on employment will be further expanded. Whether and when the creation effect comes into being depends on whether the economic scope is enlarged, whether the industrial structure is upgraded and the application effect of new technology, new product and service. Compared with the substitution effect, these factors can not be achieved in a short time. There will be many challenges in this process. It is necessary to further analyze the current situation of the application of artificial intelligence from the theory, find out the problems, and give the countermeasures and suggestions.

\section{EMPIRICAL ANALYSIS: THE APPLICATION OF ARTIFICIAL INTELLIGENCE IN CHINA}

\subsection{The development stage of artificial intelligence in China}

Compared with the development of western artificial intelligence, Chinese artificial intelligence started late. Cai Zi xing detailed analysis of the development of artificial intelligence at each stage in his article "China Artificial Intelligence 40 Years". In the 1950s and 1960s, under the influence of "pseudoscience" and "revisionism" of artificial intelligence in the Soviet Union, China strongly criticized artificial intelligence. At the beginning of the reform and opening - up , Deng Xiaoping put forward " science and technology is productive force ", and China started the artificial intelligence after sending overseas students to study the artificial intelligence and set up the artificial intelligence society. In the mid to late 1980s, with Deng Xiaoping's instructions: "The popularization of computers must start with children." Artificial intelligence has been included in the national high-tech research and development program. Since then, it has ushered in dawn and embarked on a relatively normal development path. After entering the 21st century, more and more national artificial intelligence projects have sprung up and entered the stage of vigorous development.

3.2 Analyzing the overall effect of artificial intelligence on employment in China from the point of view of reality.

\subsubsection{The momentum of development is swift and violent, stimulating the demand for employment}

At this stage, artificial intelligence is developing rapidly in China. Baidu Alibaba and Tencent, represented by the e-commerce industry, are all optimistic about it. And invest a lot of manpower, material resources and financial resources in its development. Li Yanhong focuses on driverless research, the realization of Ma Yun unmanned supermarket and Ma Huateng's Tencent AI Lab, all of these led the domestic artificial intelligence market. According to statistics, hundreds of startups have emerged in the domestic market, dedicated to intelligent development research in various segments. The shortage of high-end talents will undoubtedly hinder the pace of their research, so the demand for 
professionals and scholars is surging, creating jobs and opportunities for the job market. At the same time, in a relatively equal starting line, the competition between companies and enterprises will be further magnified, and the competition for high-end talent will become more and more intense.

When artificial intelligence technology is put into use on a large scale after the development stage, the job market will not only increase the demand for high-end talents, but also require ordinary workers to change their labor skills. The first hit is some conventional, procedural workers, because weak artificial intelligence has enough technology to replace them, but also to improve labor productivity and reduce the error rate, so the replacement is overwhelming. In the near future, pure physical and procedural workers even like research assistants, translators, etc. need to re-learn new skills, and the job market for new skill owners becomes vast, which creates opportunities for expanding employment.

3.2.2 The effect of robot substitution is becoming more and more obvious, and the impact of long-term development on employment will be more and more serious.

Robots have a lot of advantages over man when they are working. For example, human beings are generally unwilling or not suitable for working in high risk and high intensity environment, and the laborers of simple and repetitive work are relatively lack. But the robot does not exist this problem, and the robot work can improve the efficiency and quality, so the substitution effect gradually appears. According to the macro research institute in twenty-first Century, it is expected that the number of manual laborers in the next ten years will be reduced by about 100 million people, the demographic dividend is reduced and the cost of labor has surged, which will usher in the climax of "machine replacement". At present, robots are mainly used in electronics, automobiles and other manufacturing industries, used as industrial robots. In the long run, with the further development and progress of artificial intelligence, its wide range of alternative human work can be foreseen.

\subsubsection{Artificial intelligence creates effect to appear, can compensate substitution effect to a certain extent}

At present, although the substitution effect of artificial intelligence and robot gradually deepens over time, the creative effect of artificial intelligence and robot is also shown. At present, robot manufacturing and research in China has begun to take shape. There are hundreds of companies and tens of thousands of employees engaged in artificial intelligence and robot research, among which technical personnel are in short supply, and relevant training work needs to be carried out urgently. At the same time, new services and jobs from robotics research and manufacturing have created new jobs, such as robot leasing, robotics technology training, and so on. According to the current situation, we need to actively develop these new industries in order to expand this kind of creative effect, so as to counteract the adverse situation brought about by robot substitution for human employment.

\section{TO ACTIVELY DEAL WITH THE CHALLENGES AND COUNTERMEASURES THAT ARTIFICIAL INTELLIGENCE HAS BROUGHT ADVERSE EFFECTS ON EMPLOYMENT}

\subsection{Strengthen the monitoring of employment unemployment and pay attention to the training of professional talents}

Both theoretically and practically, the further development of artificial intelligence and robots in China and even the expansion of some job substitution effects in the short term have become the general trend. So what can be done now is to improve your ability to adapt to it, not to avoid it. However, the quality and skills of labour force are in a backward position compared with the new technology of artificial intelligence, and there is a shortage of high-end talents, so it is urgent to train the professionals in artificial intelligence.

To strengthen the cultivation of professional talents, the government should pay attention to them, even from the point of view of colleges and universities, optimize the training programs of colleges and universities, so as to transport relevant professionals to the society. At the same time, because the speed of artificial intelligence replacing some of the labour posts is affected by many factors, and there are still unpredictable factors in the process, it is necessary to strengthen the monitoring of employment and unemployment, and to improve the early warning mechanism of unemployment, and be prepared for prevention in advance so that you can handle it calmly.

\subsection{Pay attention to the development of new industries, such as robots, and expand the creative effect of artificial intelligence}

Since the development of new technologies, such as artificial intelligence and robotics, will have destructive and creative effects on employment, and because artificial intelligence does have an advantage that human labour cannot match, the destructive effect cannot be avoided. Then we should try to expand the creative effect to counteract the damage effect. First of all, we should pay more attention to the emerging industries, and then we should strengthen the independent research and development of new technologies and improve the quality of products. The state should encourage and support the development of new industries such as artificial intelligence, robot manufacturing, etc. Promote industrial automation and intelligence. Finally, it is necessary to seize the development opportunity of the new industry, to train the technical talents it needs, and to serve for its better development.

\subsection{Improve the social security system and maintain social stability and development}

In the short term, manual and procedural labour will gradually be replaced by robots. And the professional skills they possess are certainly not suited to the needs of new jobs created by new technologies in artificial intelligence, and there is little chance of mastering high-end skills in the short term. As a result, the number of unemployed will increase with the passage of time and the further application of technology. For these unemployed people, the government should perfect the security system and support policy for the unemployed, adopt unemployment insurance or unemployment assistance and other measures to solve the unemployment problem, in order to maintain social stability.

\section{CONCLUSION}

Starting from whether artificial intelligence will cause mass unemployment, which is the current reality panic of human beings, this paper comprehensively analyzes the influence of artificial intelligence on employment by combining theory with practice. In the short run, artificial intelligence is more destructive to employment, but in the long run, it can also create jobs and create new jobs. Finally, this paper gives some thoughts and suggestions on how to make active use of the creative effect of artificial intelligence to suppress the damage effect.

\section{REFERENCES}

[1] Guanjun, W. 2017. Artificial Intelligence and Future Society: Three Reflections []]. Exploration and Contention.

[2] Boden, M. 2017. Artificial Intelligence, Unemployment and Innovation [J]. China Economic Report, 4

[3] Runhua. F. 2018. Analysis of the development of artificial intelligence on the social employment situation [J]. Contemporary economy, 4.

[4] He, Z. 2017. Labour Market Restructuring Where Artificial Intelligence Will Be Served [J]. China Business Daily, 1.

[5] Yongqian, T. 2018. Artificial intelligence, employment and the reform of China's labour policy legal system [J]. Journal of Henan University of Economics and Law, 1.

[6] Frey, C.B., Osbome, M.A. 2013. The Future of Employment: How susceptible are jobs to computerisation? Working paper, published by the Oxford Martin Programmed on Technology and Employment.

[7] Jun, W., Zhe, Z.Y. 2017. Mechanisms and Countermeasures for the Influence of New Technological Advances such as Artificial Intelligence on Employment [J]. Macroeconomic Research. 
[8] Hong, L.Y. "Intellectual Revolution: Meeting the Social, Economic, and Cultural Changes in the Age of Artificial Intelligence," CITIC Publishing House.

[9] Xing, C.Z. 2016. 40 Years of Artificial Intelligence in China [J]. Science \& Technology Review, 34 (15).

[10] Jun, W., Wei, Y. 2017. Historical Analysis and Frontier Progress of the Influence of Artificial Intelligence and Other Technologies on Employment. Economic Research Reference, 27.

[11] Jun, W., Zhe, Z.Y., Bo, Z.Y., Lian, H.Q. 2017. Countermeasures and Suggestions on the Impact of Artificial Intelligence on Employment. China Economic and Trade Review, 24.
[12] Jie, S.Z. 2017. Philosophical Considerations on the Development of Artificial Intelligence. Qi l u Journal, 1.

\section{ABOUT THE AUTHORS}

He ping: male, August 1981, Qian jiang, Hubei Province, now vice president and associate professor of Wuhan University of Technology, Doctor of Law, Director of Chinese Society of Social Law.

GaoYao ying: female, July 1995, Changsha, Hunan Province, is currently a student of 2017 Master Faculty of Law (Illegal Studies), Wuhan University of Technology.

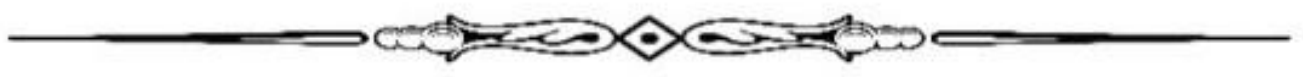

